\title{
EDUCAÇÃO E QUALIFICAÇÃO CONTINUADA DOS PROFISSIONAIS CONTÁBEIS DOS ESCRITÓRIOS DE CONTABILIDADE DE TANGARÁ DA SERRA.
}

\author{
Carla Janaine Pauly ${ }^{1}$ \\ Marcelo Evandro Alves ${ }^{2}$
}

\section{RESUMO}

As mudanças na área da contabilidade têm ocorrido constantemente, fazendo com que o profissional contábil necessite de constante aprimoramento. Sob esta perspectiva, este trabalho apresenta o resultado da pesquisa realizada nos escritórios de contabilidade de Tangará da Serra, investigando se existe interesse na Educação e Qualificação Continuada dos Profissionais e se há investimento nos mesmos frente ao mercado de trabalho. A pesquisa quanto a suas características é de caráter exploratório, de caráter descritivo e de caráter explicativo. Foram identificados fatores relevantes no cenário contábil de Tangará da Serra no que diz respeito ao perfil dos funcionários dos escritórios de Contabilidade e seus anseios perante a educação e qualificação continuada. Os resultados obtidos permitem identificar como algumas posturas afetam o mercado contábil tangaraense.

Palavras-chave: Educação; qualificação continuada; contabilidade;

\section{INTRODUÇÃO}

No início da civilização, a responsabilidade pela educação era desempenhada pela família, pelas igrejas e através do aprendizado em oficinas, que tinham a tarefa de repassar os ensinamentos, conhecimentos e costumes da época. Com o passar dos tempos surgiu um novo modelo quanto às novas exigências em relação aos conhecimentos necessários ao novo perfil do profissional, os quais não puderam ser supridos pela família ou pela igreja em conseqüência das mudanças no mercado de trabalho (MIRANDA; SOLINO 2006). Houve mudanças nos valores da sociedade e a educação passou a evoluir conforme o padrão exigido pelo mercado de trabalho. Os conhecimentos e habilidades necessários para atender as necessidades das organizações foram se tornando cada vez mais específicos, deixando de lado o foco no passado e se direcionando rumo ao futuro. Como discorrem Prosdócimo e Ohira (1999), "educação continuada é o processo contínuo de atualização, aperfeiçoamento, treinamento e aprimoramento das qualificações e habilitações individuais de cada profissional".

\footnotetext{
${ }^{1}$ Acadêmica do curso de Ciências Contábeis da UNEMAT - Campus de Tangará da Serra, carlapauly@gmail.com

${ }^{2}$ Professor do Departamento de Ciências da UNEMAT - Campus de Tangará da Serra, marcelo.evandro@unemat.br
} 
O processo da educação está evoluindo constantemente, devido às mudanças que vem dos avanços da tecnologia, levando os educadores a focalizar as necessidades atuais, criadas pela sociedade do conhecimento e da informação e pelo mercado de trabalho. Diante dessa realidade, o processo da educação continuada, onde o profissional busca a contínua atualização de seus conhecimentos, é de suma importância, por não se deixar estagnar os conhecimentos do mesmo e estando sempre atualizado com os recursos oferecidos para um melhor atendimento aos seus clientes. Deste modo este artigo visa verificar se existe interesse na área da Educação e Qualificação Continuada dos Profissionais Contábeis dos Escritórios de Contabilidade de Tangará da Serra e se há investimento nos mesmos frente ao mercado de trabalho.

Para a realização deste trabalho foram analisadas duas hipóteses:

- O Profissional Contábil procura se atualizar pela exigência legal do Governo e do Mercado de Trabalho;

- Os escritórios investem na formação dos profissionais contábeis;

Nos dias atuais, o mercado de trabalho busca profissionais na área Contábil que estejam atualizados e capacitados, que possam encaminhar as empresas por caminhos claros e menos onerosos. Para tanto há a necessidade da procura de conhecimento, que se adquire através da educação e da qualificação profissional, nele a pessoa consegue alcançar seus objetivos e sobreviver no mercado de trabalho tão competitivo, correspondendo às necessidades e as expectativas dos clientes. E para encarar esses desafios, a educação continuada apresenta-se como instrumento fundamental para o profissional contábil inserir-se e obter sucesso no mercado de trabalho. Nessa perspectiva, a relevância desta pesquisa está na contribuição para o conhecimento de uma realidade ainda pouco estudada no Município de Tangará da Serra.

Sendo assim pretende-se:

- Levantar o grau de instrução dos profissionais contábeis dos Escritórios Contábeis de Tangará da Serra;

- Verificar se os profissionais contábeis de Tangará de Serra têm conhecimento a respeito da educação continuada; 
- Pesquisar se os profissionais contábeis de Tangará de Serra buscam cursos de qualificação e educação continuada;

- Verificar junto aos funcionários dos escritórios quais cursos os profissionais contábeis devem ter para atuar no mercado de trabalho.

- Identificar se há investimento na educação e qualificação dos profissionais contábeis por parte dos escritórios de contabilidade.

\section{HISTÓRIA DA CONTABILIDADE}

A contabilidade é tão antiga quanto à própria civilização, por mais primários que possam ter sido os primeiros registros da contabilidade, o homem primitivo já dava sinais de inteligência e percepção do mundo ao seu redor. Já reconhecia, de forma primitiva, a necessidade de acompanhar a sua evolução patrimonial. E através desta necessidade deixou registrado em inscrições e pinturas rupestres suas noções de quantidade e qualidade. Com a prática dos inventários de ferramentas utilizadas para a caça e a pesca, a contagem e separação do rebanho, o homem primitivo dava os primeiros passos a uma forma rudimentar de contabilidade (IUDICIBUS, 2000; SÁ, 2005, 2006).

Para Oliveira (2006, p. 3) "Muitos dos registros descobertos pelos arqueólogos configuram as primeiras formas de assentamentos contábeis conhecidos, embora não possuam características encontradas hoje na contabilidade". De acordo com Sá (1997, p.15) “A Contabilidade nasceu com a civilização e jamais deixará de existir em decorrência dela, talvez, por isso, seus progressos quase sempre tenham coincido com aqueles que caracterizam os da própria evolução do ser humano". Segundo Iudícibus (2000, p.30) "O homem teve de ir aperfeiçoando seu instrumento de avaliação da situação patrimonial à medida que as atividades foram desenvolvendo-se em dimensão e em complexidade”.

Foi entre os sumérios e os babilônicos que surgiram as primeiras manifestações técnicas de contabilidade, entre estas primeiras manifestações dá-se destaque para o livro Diário que surgido nesta época, na Suméria eram feitos em tabuletas de argila onde eram registrados os fatos contábeis ocorridos; o livro Razão surgiu com a união das tabuletas, separadas por grupo de contas, que eram furadas e amarradas segundo a natureza de cada conta. (OLIVEIRA, 2006; SÁ, 2005;). Como ocorreu em todos os ramos da ciência, a 
Contabilidade evoluiu vagarosamente, porém apoiada em bases sólidas. Vários povos ao redor do mundo se desenvolveram quase que ao mesmo tempo, mas foi entre os Sumérios que o desenvolvimento foi mais enfático.

No ramo da contabilidade uma das evoluções que mais se tornaram importantes no decorrer dos anos, foi o chamado método das partidas dobradas, que veio a surgir ainda na idade média, e onde para cada débito existe um ou mais créditos fechando os valores respectivos a aplicação e origem dos recursos (SÁ, 2005). Há grande discussão entorno da autoria e da conceituação do Método das Partidas Dobradas. O que se sabe é que surgiu no mundo antigo e que várias culturas e civilizações devem, ter chegado a essa definição lógica em tempos semelhantes. (OLIVEIRA, 2006).

A disseminação do conhecimento contábil se deu no início através da oralidade, assim como se difundiam naturalmente os mais diversos ramos do saber. Mais do que um mero registro das origens e aplicações dos recursos, a contabilidade é um dos principais instrumentos de gestão patrimonial (IUDÍCIBUS,2000; SÁ, 2006).

Segundo Sá (2005, p. 29):

A partir da primeira metade do século XIX, portanto, estruturou-se uma vigorosa doutrina que tinha por objetivo conhecer as relações que existem entre os acontecimentos da riqueza patrimonial e como explicar o que acontecem com esta, a partir das referidas relações.

Para Oliveira (2006, p. 16):

O mundo moderno necessita cada vez mais de controles e de informações amplas, completas e precisas sobre os meios de produção, empresa e capital, e a Contabilidade é a ciência que possui todos os instrumentos e condições para atender a essas necessidades.

\section{OBJETIVOS DA CONTABILIDADE}

O objetivo da contabilidade não sofreu alteração ao longo dos anos. Houve inúmeras modificações no que tange a forma das demonstrações devido ao vínculo existente entre às mudanças sociais que ocorrem ao longo dos anos e que a cada nova mudança exige-se da contabilidade nova postura nas divulgações geradas. As mudanças também se dão de acordo com os tipos de usuário e as formas de informação que tem sido demandada pelos mesmos. Os principais objetivos da contabilidade são o controle do patrimônio e o fornecimento de informações de ordem econômica e financeira sobre o mesmo para que se tornem mais fáceis 
e seguras as tomadas de decisões feitas pelos usuários da contabilidade. (IUDÍCIBUS, 1997; PADOVEZE, 2004; RIBEIRO, 2005). No ponto de vista desses autores pode-se concluir que o desenvolvimento da Contabilidade esta atrelado, a necessidade de fornecer informações a cerca do patrimônio e suas mutações, de forma clara e exata para orientar as tomadas de decisões e propiciar um controle eficiente da situação patrimonial da empresa.

\subsection{CONTABILIDADE NO BRASIL}

De acordo com Schmidt (2000, p. 205) "A Contabilidade brasileira, pode ser dividida em dois estágios de desenvolvimento: anterior a 1964 e posterior a 1964”.

\subsubsection{ANTES DE 1964}

Em 1808 aconteceu uma das primeiras manifestações contábeis brasileiras, ocorreu no reinado de D. João VI, quando foi publicado um alvará obrigando os contadores gerais da real fazenda a aplicarem o método das partidas dobradas na escrituração mercantil. (SANTOS; SCHIMIDT; MACHADO, 2005). Percebe-se que, desde o inicio, fica clara a interferência da legislação na evolução Contábil no Brasil. Essa interferência dá-se a inoperância, o governo sempre teve que tomar a iniciativa. De acordo com Santos, Schimidt e Machado (2005 p. 88): "Uma das primeiras manifestações da legislação foi o código comercial de 1850, que instituiu a obrigatoriedade da escrituração contábil e da elaboração anual da demonstração do Balanço Geral". Segundo, Schimidt (2000, p.209):

Essa primeira fase de desenvolvimento da Contabilidade nacional foi marcada por aspectos relevantes: a intervenção da legislação no desenvolvimento de procedimentos contábeis e a influência doutrinária das escolas italianas.

\subsubsection{DEPOIS DE 1964}

Em 1964 teve início a segunda etapa do desenvolvimento da Contabilidade brasileira, ano em que o professor José da Costa Boucinhas introduziu um novo método de ensino de Contabilidade. Boucinhas adotou o método didático norte americano, a influência dos autores italianos e das escolas de pensamento italiana foi sendo substituída pelos norte-americanos. (IUDICIBUS, 2006 p. 42-43).

Para que o Progresso do contador seja constante, duradouro e equilibrado, devem ser trabalhados profundamente os Princípios contábeis pelas entidades representativas da profissão, e que os técnicos procurem se graduar em bons cursos de Ciências Contábeis, e as instituições de ensino superior se dediquem mais a pesquisa contábil (IUDICIBUS, 2006 p. 43-44).

Revista UNEMAT de Contabilidade, ano 1, n.1, jan./jun. 2012. 
De 1964 a 1976 foi marcado por um período de desenvolvimento da chamada escola de correção monetária. Foi a segunda fase no desenvolvimento desta contribuição genuinamente nacional. A Lei $\mathrm{n}^{\circ}$ 4.357, de 16 de Julho de 1964, tornou obrigatória a correção monetária do ativo imobilizado e do capital das pessoas jurídicas. Houveram muitas críticas, devidas aos seus objetivos de fiscalização, mas trouxe para a Contabilidade um instrumento que resolve as enormes distorções causadas pela inflação nos relatórios contábeis e também instituiu a depreciação do valor corrigido do imobilizado, onde representa a realidade dos bens das empresas.

\title{
3.2 CONSELHO FEDERAL DE CONTABILIDADE - C F C
}

Conforme descrito no site do CFC:

O Conselho Federal de Contabilidade, criado pelo Decreto-lei no 9.295/46, de 27 de maio de 1946, constitui-se pessoa jurídica de direito privado que, por delegação, presta serviço público, tendo sede e foro na cidade de Brasília (DF).Sua estrutura, organização e funcionamento são estabelecidos no Estatuto dos Conselhos de Contabilidade, regulamentado pela Resolução CFC $n^{\circ} 825$, esta revogada pela Resolução CFC no 882, de 29 de junho de 2000, e, posteriormente, pela Resolução CFC n 903, publicada no Diário Oficial de União no dia 13 de junho de 2001, a qual continua em vigor. O CFC, integrado, no mínimo, por um representante de cada Unidade da Federação e respectivo suplente, tem por finalidade, nos termos da legislação em vigor: Orientar, normatizar e fiscalizar o exercício da profissão contábil, por intermédio dos Conselhos Regionais de Contabilidade, cada um em sua base jurisdicional, nos Estados e no Distrito Federal; Representando os CRCs, e sob a forma de Conselho Especial de Tomada de Contas, examinar e julgar as contas do CFC, organizadas e prestadas por seu Presidente.

\subsection{CONSELHO REGIONAL DE CONTABILIDADE DE MATO GROSSO CRC/MT.}

De acordo com o CRC

\begin{abstract}
Art. $1^{\circ}$ - O Conselho Regional de Contabilidade de Mato Grosso - CRCMT é constituído de 12 (Doze) membros e igual número de suplentes, eleitos na forma da legislação vigente, observada a proporção de $2 / 3$ (dois terços) de Contadores e 1/3 (um terço) de Técnicos em Contabilidade, constituindo-se numa entidade fiscalizadora do exercício profissional, exercendo um serviço público, por delegação do poder público, mediante autorização legislativa.
\end{abstract}

O CRC/MT é uma extensão do CFC, sendo que em cada Unidade da Federação existe uma representação do CFC.

\subsection{NOVO CÓDIGO CIVIL}

Conforme o Código Civil: 
Art. 1.177. Os assentos lançados nos livros ou fichas do preponente, por qualquer dos prepostos encarregados de sua escrituração, produzem, salvo se houver procedido de má-fé, os mesmos como se o fossem por aquele.

Parágrafo único. No exercício de suas funções; os prepostos são pessoalmente responsáveis, perante os preponentes, pelos atos culposos; e, perante terceiros, solidariamente com o preponente, pelos atos dolosos.

Art. 1.178. Os preponentes são responsáveis pelos atos de quaisquer prepostos, praticados nos seus estabelecimentos e relativos à atividade da empresa, ainda que não autorizados por escrito.

Parágrafo único. Quando tais atos forem praticados fora do estabelecimento, somente obrigarão o proponente nos limites dos poderes conferidos por escrito, cujo instrumento pode ser suprido pela certidão ou cópia autêntica do seu teor.

Art. 1.179. O empresário e a sociedade empresário são obrigados a seguir um sistema de contabilidade, mecanizado ou não, com base na escrituração uniforme de seus livros, em correspondência com a documentação respectiva, e a levantar anualmente o balanço patrimonial e o resultado econômico.

\section{EDUCAÇÃO CONTINUADA}

Figueiredo e Lima (1986 apud MIRANDA; SOLINO 2006) consideram a educação continuada como formação, aperfeiçoamento integral com transferência de conhecimentos e práticas de usos e costumes, ou seja, é um procedimento amplo relacionado com valores, atitudes e motivação. Macedo (1985 apud MIRANDA; SOLINO 2006) define a educação continuada como um processo começado pelo indivíduo na infância e continuado durante toda sua vida, ou seja, é um processo permanente de educação.

A educação continuada tem a sua importância, não somente na área do conhecimento, em constante modificação, mas principalmente no que diz respeito aos valores, atitudes e motivação do individuo; por ser prestador de serviços contábeis necessita estar em consonância direta com o conhecimento das normas e legislações vigentes e suas constantes modificações, para que possa prestar um serviço de excelente qualidade e sem causar ônus para seus clientes tomadores de serviço.

De acordo com Prosdócimo e Ohira (2000 apud MIRANDA; SOLINO 2006), a educação continuada prepara o indivíduo para executar melhor aquilo que já realiza, focalizar o como fazer, capacitando-o para atuar na realidade atual como também, para o futuro. Conforme Miranda e Solino (2006) "a educação continuada pode ser praticada de diversas formas: participação em seminários, congressos, conferências ou ciclos de debates; leitura de trabalhos de congressos publicados em anais, livros e periódicos especializados nacionais e estrangeiros." É de extrema importância que o indivíduo não considere apenas os cursos de graduação, pós-graduação, mestrado e doutorado como modos de educação constante e 
continuada, toda e qualquer forma que o indivíduo encontre para buscar o aperfeiçoamento de suas práticas contábeis devem ser consideradas como forma de educação continuada. Guimarães (1997apud MIRANDA; SOLINO 2006) aponta como maior serviço de educação continuada a necessidade de produzir literatura na área da informação para manter o profissional atualizado, de maneira a desafiá-lo, estimulá-lo, deixá-lo em contato permanente com o desenvolvimento científico voltado à sua área.

Já Tarapanoff (1988 apud MIRANDA; SOLINO 2006) concorda que essa responsabilidade compete ao próprio profissional a fim de eliminar lacunas de formação e de se atualizar / reciclar em relação à demanda específica.

De acordo com Bezerra (2009)

Desta maneira percebemos a importância da educação continuada da contabilidade, tanto aos profissionais encontrados no mercado, quanto aos professores $\mathrm{e}$ universidades para darem um estudo de qualidade aos futuros profissionais, enfatizando a necessidade da contabilidade gerencial, de custos e financeira, fornecendo informações valiosas aos empresários sobre o andamento de seus negócios e a saúde de seu patrimônio.

\section{METODOLOGIA}

Neste tópico será apresentada a pesquisa de acordo com suas características, como ocorreu a coleta e tratamento dos dados e a forma de aplicação da pesquisa de campo. Oliveira (2006 p.135) diz: "Método nada mais é que o caminho a ser percorrido pra atingir o objetivo proposto."

Quanto a suas características, a pesquisa foi realizada em três fases, sendo a primeira de caráter exploratório em fontes primárias (Pesquisa de campo) e em fontes secundárias (Pesquisa bibliográfica); a segunda fase de caráter descritivo consiste na aplicação de questionário, tabulação e descrição dos dados coletados; a terceira fase com caráter explicativo consiste na interpretação e análise dos fatos coletados, na elaboração das conclusões da pesquisa e relatório de resultados, onde serão expostos os resultados e as conclusões acerca dos objetivos propostos. 


\section{Delimitações da Área}

A pesquisa foi aplicada com 215 funcionários dos 37 escritórios de contabilidade de Tangará da Serra (Conforme Relação de Escritórios Contábeis fornecida Pela 16a Delegacia do CRC-MT).

\section{Dados Primários}

Os Dados Primários foram coletados por meio de questionários, os quais foram aplicados aos funcionários, proprietários e responsáveis dos 37 escritórios de contabilidade de Tangará da Serra. O questionário foi composto de perguntas fechadas a respeito do perfil do entrevistado e da educação e qualificação continuada dos profissionais da contabilidade em Tangará da Serra - MT

No momento da tabulação dos dados coletados, os questionários foram analisados observando os objetivos definidos para o trabalho e de forma crítica, com o objetivo de identificar possíveis erros que viessem a adulterar o resultado da pesquisa.

As visitas realizadas nos Escritórios Contábeis de Tangará da Serra ocorreram no dia 26 de Agosto de 2011, onde foram aplicados os questionários com os funcionários e os responsáveis pelos escritórios. A pesquisa foi bem recebida, e respondida a contento.

\section{Dados Secundários}

Os dados secundários dizem respeito à pesquisa bibliográfica e servem de embasamento teórico para a confecção e aplicação da pesquisa. Os dados secundários foram coletados através de pesquisa bibliográfica, realizada em abril e maio de 2011. As quais estão registradas neste artigo no item Referencial Teórico.

\section{DISCUSSÃO DE RESULTADOS}

Através de questionário aplicado a população de 215 funcionários dos 37 escritórios de Tangará da Serra, buscou-se a principio identificar o perfil do profissional contábil que atua nos escritórios contábeis tangaraenses, mostrando:

- Que 75,65\% dos entrevistados tem idade inferior a 30 anos;

- Outros $19,13 \%$ dos entrevistados tem idade entre 31 e 40 anos; 
- E apenas 5,22\% dos entrevistados tem idade superior a 41 anos.

- Que $61,21 \%$ dos entrevistados são do sexo feminino e $38,79 \%$ são do sexo masculino.

Com os dados acima pode-se identificar o perfil do profissional contábil no Município de Tangará da Serra, sendo ele composto em sua maioria por funcionários do sexo feminino e jovens com idade inferior a 30 anos.

Quanto ao perfil dos responsáveis pelos escritórios de contabilidade, percebe-se:

- Que 83,34\% são do sexo masculino e apenas 16,66\% são do sexo feminino.

Quanto a idade:

- $50 \%$ dos responsáveis possuem entre 30 e 40 anos;

- $16,66 \%$ dos mesmos possuem entre 41 e 50 anos; e

- $33,34 \%$ possuem mais de 50 anos.

O nível de formação dos funcionários dos escritórios pode ser dividido entre 80,87 \% dos profissionais que buscaram e buscam a profissionalização e 19,13 \% que não se profissionalizaram. Os funcionários que buscaram a profissionalização podem ser visualizados no Gráfico 1:

Gráfico 1 - Nível De Formação Dos Funcionários 


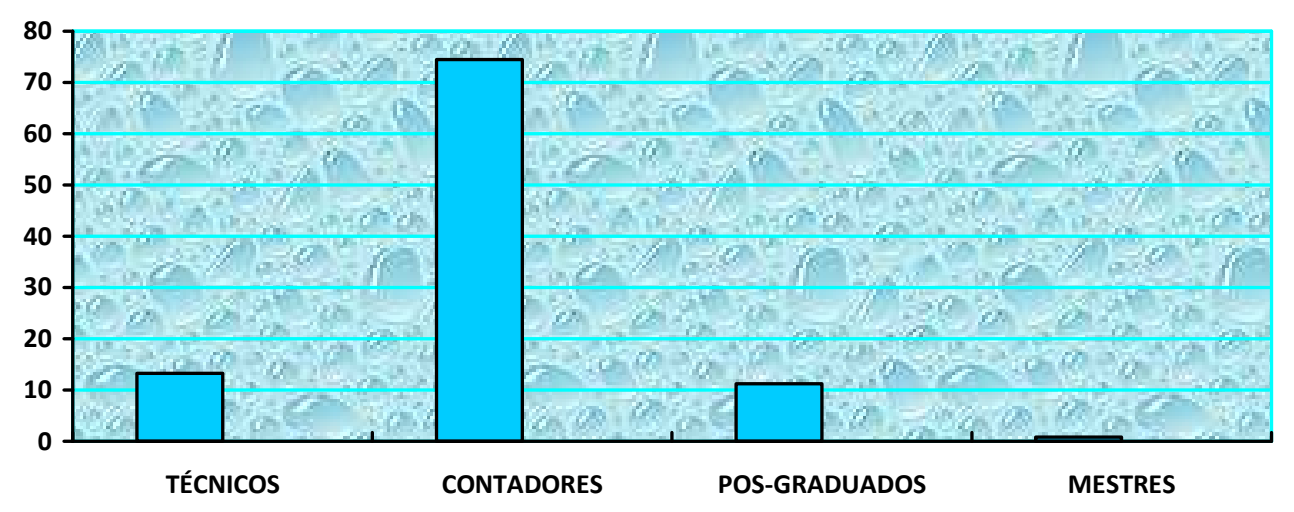

Fonte. Dados da pesquisa

Já para os responsáveis pelos escritórios, $40 \%$ têm ensino técnico e $60 \%$ ensino superior.

No que tange a preocupação do funcionário quanto a importância da educação e qualificação continuada do profissional contábil que atua nos escritórios de Tangará da Serra, 95,65\% dos entrevistados consideram importante a busca pela qualificação contínua dos profissionais, enquanto que 3,48\% acham provável esta importância e 0,87\% dos entrevistados não consideram importante a qualificação continuada dos profissionais Contábeis. Quanto aos responsáveis pelos escritórios $100 \%$ consideram importante a qualificação continuada de seus funcionários, e entre eles $50 \%$ consideram fundamental e os outros $50 \%$, essencial.

Quanto à área em que os profissionais contábeis entrevistados atuam nos Escritórios de Contabilidade identificou-se que estão divididos segundo os percentuais abaixo:

- $39,49 \%$ Na área Fiscal;

- $38,22 \%$ Na Área Contábil;

- $18,47 \% \mathrm{Na}$ Área Pessoal; e

- $3,82 \%$ Em outras áreas.

Com a leitura destes percentuais percebe-se que as áreas que mais investem em pessoal, são as áreas Fiscal e Contábil.

Quando perguntado em que áreas da contabilidade os funcionários percebiam maior necessidade de aprimoramento, colheram-se os seguintes resultados:

- 52,14\% na área Fiscal; 
- 30\% na Área Contábil;

- $17,86 \%$ Na Área Pessoal;

Para os responsáveis pelos escritórios este percentual difere um pouco sendo 14,30\% na área pessoal; $42,85 \%$ na área fiscal e $42,85 \%$ na contabilidade.

Em relação as oportunidades de cursos disponíveis na área contábil em Tangará da Serra, obtiveram-se os resultados apresentados no gráfico 2 :

Gráfico - 2: Oportunidades De Cursos

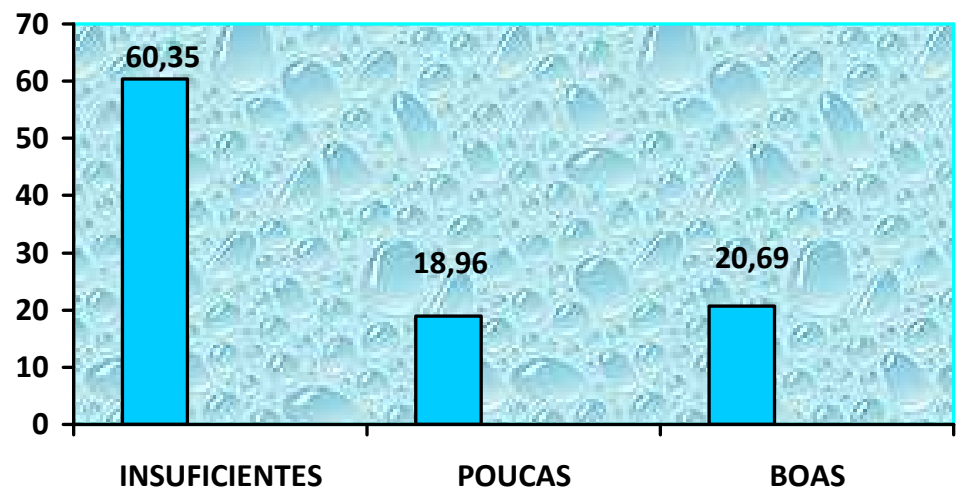

esentado no gráfico 2, identifica-se que os profissionais contábeis de Tangará da Serra estão insatisfeitos com as oportunidades de cursos disponíveis na cidade e ressaltaram a dificuldade de buscar cursos fora da mesma; de acordo com os entrevistados, os cursos de qualificação são razoavelmente caros, custando cerca de $\mathrm{R} \$ 300,00$ em média por 8 horas de curso( informação cedida pela empresa Carvechi e Cinat), e existem as despesas com transporte, hospedagem e alimentação que tornam o custo muito elevado.

Quando questionados em relação a quais profissionais deveriam buscar a qualificação constante, os resultados obtidos são de 5,64\% que acreditam que são os Profissionais da Área Pessoal; Já para 8,87\% dos entrevistados são os Profissionais da Área Fiscal; Para 7,26\% são os Profissionais da área Contábil que deveriam buscar a qualificação constante; de acordo com 77,42\% dos entrevistados Todos os Profissionais devem buscar o aprimoramento; e apenas $0,81 \%$ acreditam que o aprimoramento deve ser feito pelas pessoas que possuem Cargos de Chefia. E para os responsáveis pelos escritórios, 100\%, ou seja, todos os profissionais devem se qualificar. 
Em relação ao funcionário, se ele se interessa na atualização profissional, através da qualificação continuada, $91,15 \%$ dos entrevistados responderam que sim; e 8,85\% dos entrevistados disseram que não. Enquanto os responsáveis, $100 \%$ procuram se atualizar sempre. Quanto à freqüência dessa atualização, os dados podem ser verificados no gráfico 3.

Gráfico 3 - Frequencia De Cursos

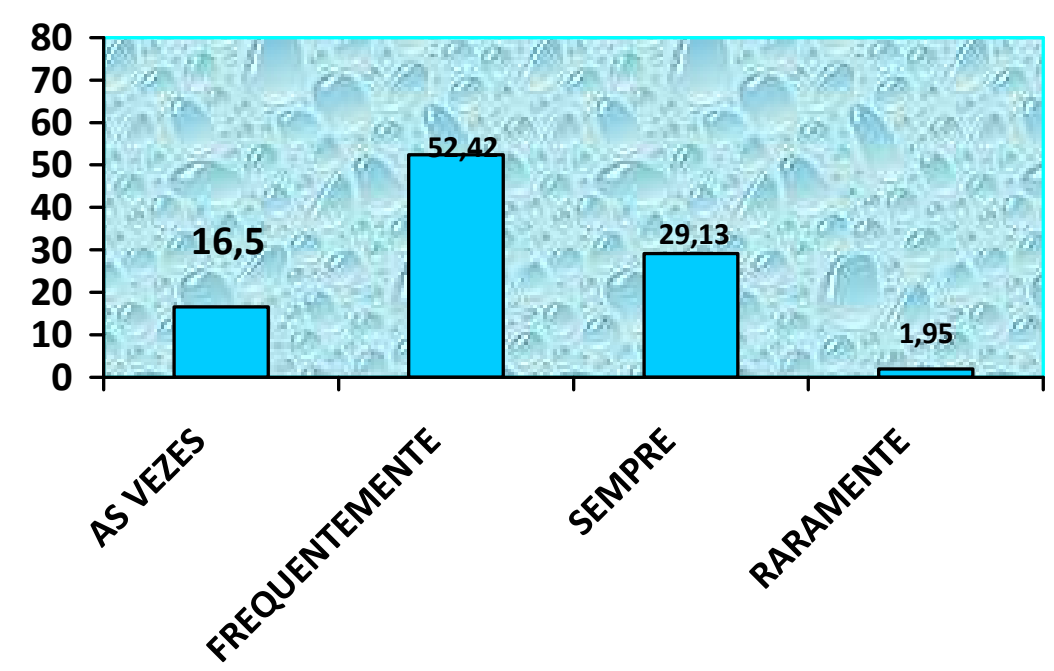

Fonte: Dados da pesquisa

Em contrapartida quando questionados se os funcionários possuem algum curso de qualificação continuada, nota-se que os resultados diferem dos dados apresentados acima, como se pode analisar no gráfico 4:

Gráfico 4 - Funcionários Que Possuem Cursos De Qualificação

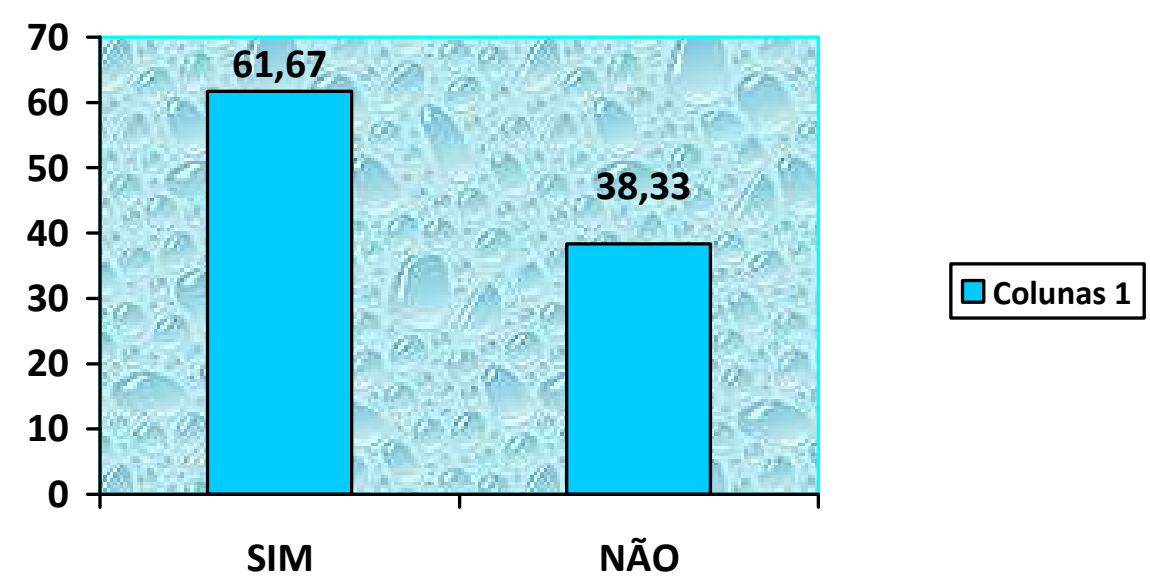

Fonte: Dados da pesquisa

Dessa forma se percebe que os profissionais Contábeis de Tangará da Serra têm interesse em se atualizar, e estão fazendo isso, por meio de pesquisas em livros, em periódicos 
e principalmente em redes de busca na internet. Isso ocorre pelo citado anteriormente a respeito da falta de cursos de qualificação continuada no município e pelo alto custo que acarreta a saída para outros municípios em busca da qualificação.

Aos funcionários que possuem curso de qualificação continuada, foi indagado em que áreas eles possuem estes cursos, com objetivo de identificar quais as áreas são mais procuradas para cursos. As áreas mais procuradas foram as áreas de pessoal e fiscal. Os resultados podem ser verificados no gráfico 5:

Gráfico 5- Áreas Dos Cursos De Qualificação

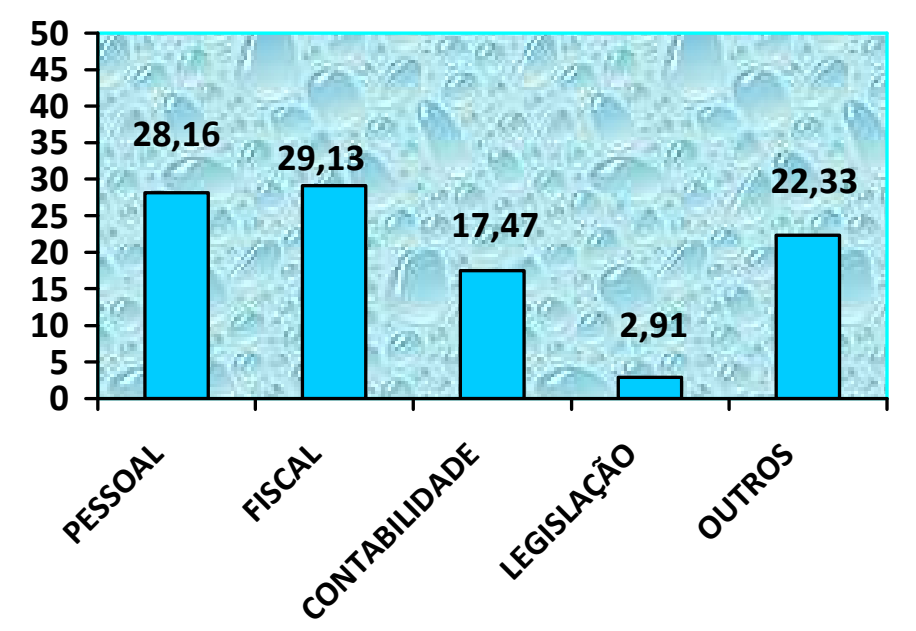

Fonte: Dados da pesquisa

Os funcionários também foram questionados a respeito do incentivo e do investimento por parte do escritório para a qualificação continuada, no qual $87,18 \%$ responderam que o escritório incentiva a qualificação continuada e 12,82\% disseram que o escritório não incentiva a mesma. Em relação ao investimento, foi questionada a frequência do mesmo segundo os funcionários, e os resultados foram os seguintes:

- $10 \%$ confirmam que raramente há investimento;

- $40 \%$ disseram que às vezes há investimento;

- $23,64 \%$ relataram que há investimento com frequência; e

- $26,36 \%$ afirmam que sempre há investimentos.

Na visão dos responsáveis:

- $33,34 \%$ as vezes; e

- $66,66 \%$ com frequência. 


\section{CONSIDERAÇÕES FINAIS}

Os escritórios contábeis de Tangará da Serra têm as suas equipes formadas na maior parte por jovens sedentos de conhecimento; e esta sede de conhecimento não se sacia somente com o curso de graduação em Ciências Contábeis, muito pelo contrário, a graduação faz com que estes profissionais abram seus horizontes e vejam quão grande é o leque de informações necessárias e pertinentes ao contabilista perante o mercado de trabalho.

Durante a aplicação dos questionários, realizado com os funcionários dos escritórios de contabilidade de Tangará da Serra, houve muitas solicitações para que a UNEMAT (Universidade do Estado de Mato Grosso) se preocupe com a qualidade do profissional que está colocando no mercado; que volte seus olhos para os escritórios de contabilidade, e busque junto a estes quais as maiores dificuldades encontradas pelos jovens que saem da academia e ingressam no mercado de trabalho. Os entrevistados também sugeriram que o curso esteja sempre atualizado no âmbito da legislação, nas normas e procedimentos contábeis, tanto no que diz respeito às áreas contábil e pessoal como a área fiscal, e esta última principalmente no que se refere ao fisco estadual.

Percebe-se que o mercado de trabalho contábil em Tangará da Serra não está estagnado, está em busca de aprimoramento constante devido a exigência do governo e do próprio mercado de trabalho, validando assim a primeira hipótese deste trabalho. Pode-se também identificar que há sim investimentos em qualificação continuada por parte dos escritórios de contabilidade, nos profissionais atuantes no mercado e que estejam em busca deste conhecimento. Sendo assim a segunda hipótese deste trabalho também foi validada.

Quanto aos objetivos pode-se identificar por meio da discussão de resultados que todos foram alcançados a contento:

- Levantou-se o grau de instrução dos profissionais contábeis dos Escritórios Contábeis de Tangará da Serra;

- Verificou-se que os profissionais contábeis de Tangará de Serra têm conhecimento a respeito da educação continuada;

- Identificou-se que os profissionais contábeis de Tangará de Serra buscam cursos de qualificação e educação continuada; 
- Verificou-se junto aos funcionários dos escritórios quais cursos os profissionais contábeis devem ter para atuar no mercado de trabalho, tendo destaque a área pessoal e a área fiscal.

Identificar se há investimento na educação e qualificação dos profissionais contábeis por parte dos escritórios de contabilidade

Por parte dos responsáveis pelos escritórios de contabilidade, surgiu a solicitação que a delegacia do CRC( Conselho regional de contabilidade) se una com a UNEMAT na preocupação com o profissional contábil de Tangará da Serra, e proporcionem cursos de educação e qualificação continuada para os mesmos.

Esta necessidade do mercado revelada no presente artigo mostra o caminho a ser percorrido daqui em diante para formar profissionais que atendam a necessidade do mercado da contabilidade em constante modificação. 


\section{REFERÊNCIAS BIBLIOGRÁFICAS}

BEZERRA, Alexander Mendes. A Importância da educação continuada a contabilidade: banco de dados. Disponível em <http://www.administradores.com.br/informe-se/artigos/aimportancia-da-educacao-continuada-a-contabilidade/27851/ > Acesso em 20 de maio de 2011

CFC-CONSELHO FEDERAL DE CONTABILIDADE: Banco de dados. Disponível em <http:// http://www.cfc.org.br> Acesso em 07/05/2011 as 8:25 hs.

CFC-CONSELHO FEDERAL DE CONTABILIDADE: Princípios Fundamentais e

Normas brasileiras de contabilidade. Brasília: CFC. 2003.

FRANCO, Hilário. Contabilidade geral. São Paulo: Editora Atlas, 1997.

IUDÍCIBUS, Sérgio. Teoria da contabilidade. 5º ed. São Paulo: Editora Atlas, 1997.

IUDÍCIBUS, Sérgio. Teoria da contabilidade. $6^{\circ}$ ed. São Paulo: Editora Atlas, 2000.

IUDÍCIBUS, Sérgio. Teoria da contabilidade. $8^{\circ}$ ed. São Paulo: Editora Atlas, 2006.

MIRANDA, Ana Cláudia Carvalho de; SOLINO Antônia da Silva. Educação continuada e mercado de trabalho: um estudo sobre os bibliotecários do Estado Rio Grande do Norte.

Revista Perspectiva em Ciências da Informação. vol.11 No 3 Belo

Horizonte Sept./Dec. 2006.

OLIVEIRA, Antonio Benedito Silva. Métodos e Técnicas de Pesquisa em Contabilidade. São Paulo: Editora Saraiva 2006.

PADOVEZE, Clovis Luiz. Manual de Contabilidade Básica. $5^{\circ}$ ed. São Paulo: Editora Atlas, 2004.

PROSDÓCIMO, Zulma Pures Alves; OHIRA, Maria Lourdes Blatt. Educação continuada do bibliotecário: revisão de literatura. Revista ACB: Biblioteconomia em Santa Catarina, Florianópolis (Brasil) - ISSN 1414-0594 Vol. 4, No 4 (1999): ISSN: 1414-0594.

RIBEIRO, Osni Moura. Contabilidade básica. São Paulo: Editora Saraiva, 2005.

SÁ, Antônio Lopes de. História geral e das doutrinas da contabilidade. São Paulo: Editora Atlas, 1997.

SÁ, Antônio Lopes de. Teoria da contabilidade. $4^{\circ}$ ed. São Paulo: Editora Atlas, 2006.

SÁ, Antônio Lopes de. Fundamentos da contabilidade geral. $2^{\circ}$ ed. São Paulo: Editora Juruá, 2005.

SANTOS, José Luiz dos. SCHIMIDT, Paulo. MACHADO, Nilson Perinazzo. Fundamentos da teoria da contabilidade. São Paulo: Editora Atlas, 2005.

SCHIMIDT, Paulo. História do pensamento contábil. Porto Alegre: Editora Artes Médicas Sul, 2000. 